Article

\title{
On Iterative Methods for Solving Nonlinear Equations in Quantum Calculus
}

\author{
Gul Sana ${ }^{1}$ (D), Pshtiwan Othman Mohammed ${ }^{2, * \mathbb{D}}$, Dong Yun Shin ${ }^{3, *}$, Muhmmad Aslam Noor ${ }^{1}$ (D) \\ and Mohammad Salem Oudat ${ }^{4}$ \\ 1 Department of Mathematics, COMSATS University Islamabad, Islamabad 44000, Pakistan; \\ gulsana123@yahoo.com (G.S.); noormaslam@hotmail.com (M.A.N.) \\ 2 Department of Mathematics, College of Education, University of Sulaimani, \\ Sulaimani 46001, Kurdistan Region, Iraq \\ 3 Department of Mathematics, University of Seoul, Seoul 02504, Korea \\ 4 Administrative Sciences, Accounting and Finance, Applied Science University, Al Eker 1048, Bahrain; \\ mohammad.oudat@asu.edu.bh \\ * Correspondence: pshtiwansangawi@gmail.com (P.O.M.); dyshin@uos.ac.kr (D.Y.S.)
}

check for updates

Citation: Sana, G.; Mohammed, P.O.;

Shin, D.Y.; Noor, M.A.; Oudat, M.S

On Iterative Methods for Solving

Nonlinear Equations in Quantum

Calculus. Fractal Fract. 2021, 5, 60

https://doi.org/10.3390/

fractalfract5030060

Academic Editor: Mark Edelman

Received: 10 May 2021

Accepted: 21 June 2021

Published: 25 June 2021

Publisher's Note: MDPI stays neutral with regard to jurisdictional claims in published maps and institutional affiliations.

Copyright: (c) 2021 by the authors. Licensee MDPI, Basel, Switzerland. This article is an open access article distributed under the terms and conditions of the Creative Commons Attribution (CC BY) license (https:// creativecommons.org/licenses/by/ $4.0 /)$.

\begin{abstract}
Quantum calculus (also known as the $q$-calculus) is a technique that is similar to traditional calculus, but focuses on the concept of deriving $q$-analogous results without the use of the limits. In this paper, we suggest and analyze some new $q$-iterative methods by using the $q$-analogue of the Taylor's series and the coupled system technique. In the domain of $q$-calculus, we determine the convergence of our proposed $q$-algorithms. Numerical examples demonstrate that the new $q$-iterative methods can generate solutions to the nonlinear equations with acceptable accuracy. These newly established methods also exhibit predictability. Furthermore, an analogy is settled between the well known classical methods and our proposed $q$-Iterative methods.
\end{abstract}

Keywords: Taylor's series in q-calculus; iterative methods; convergence analysis; Daftardar-GejjiJafari decomposition technique

\section{Introduction}

In most scientific and engineering applications, the problem of finding the solution of nonlinear equations have become an active area of research. Many researchers have explored various order iterative methods to find solutions of the nonlinear equations using various techniques such as homotopy perturbation technique, variational iterative methods and decomposition technique, for details, see [1-11]. Firstly, Traub [12] initiated the study of the iterative methods for the solution of the nonlinear equations and introduced a basic quadratic convergent Newton iterative method for the solution of the nonlinear equations, which have much significance in the literature. Later on, in order to improve efficiency and local order of convergence of the Newtons method, Cordero and Torregrosa [13], Frontini and Sormani [14], Hasanov [15], Weerakoon and Fernando [16] and Ozban [17] have presented different modifications of the Newton's method using quadrature rules. Daftardar-Gejji and Jafari [18] have used different modifications of Adomian decomposition method [19] and suggested a simple technique that does not need derivative evaluation of the Adomian polynomial, which is major advantage of using this technique over Adomian decomposition method. Saqib and Iqbal [20] and Ali et al. [21,22] have used this decomposition technique and developed a family of iterative methods with better efficiency and convergence order for solving the nonlinear equations. This study shifts the paradigm of determining higher order iterative methods for solving the nonlinear equations towards the $q$-analogue of the iterative methods in the $q$-calculus.

In the last quarter of the 20th century, $q$-calculus appeared as an amalgamation of mathematics and physics (see [23-29]), and much consideration has been given by many researchers because of its wide range of applications in many fields of mathematics such 
as combinatorics, theory of relativity, mechanics, number theory and orthogonal polynomials. Firstly, Jackson [30] introduced the $q$-Taylor's formula. Then, Jing and Fan [31] derived $q$-Taylor's formula with its $q$-remainder by using the $q$-differentiation approach and established results on the $q$-remainder in the $q$-Taylor's formula. Ernest [32] presented the four different $q$-Taylor's formulas along with $q$ integral remainder. Prashant et al. [33] have used the $q$-Taylor's formula and investigated the $q$-analogue of the iterative methods, particularly the $q$-analogue of generalized Newton Raphson method and the $q$-analogue of the Newton Raphson method for the solution of algebraic transcendental equations and compared the accuracy of the results obtained by the classical methods. Many linear and nonlinear models appearing in science and engineering problems can be modeled by using the $q$ differential equations. Jafari et al. [34] have adopted Daftardar decomposition technique for solving the $q$ difference equations and also determined the convergence of the method.

In this study, we determine the $q$-analogue of the iterative methods proposed and suggested by Noor and Noor [35] and Ullah et al. [36] with the help of the $q$-Taylor's series and decomposition technique [14].

Now, we recall some of the basic results in the area of the $q$-calculus [37] for $0<q<1$ that will support the development of our proposed $q$-iterative methods for the solution of the nonlinear equations.

Let $q \in(0,1)$ the $q$-integer be defined as:

$$
\begin{aligned}
& {[n]_{q}=1+q+q^{2}+\cdots+q^{n}-1=\frac{1-q^{n}}{1-q} \quad \text { for } n=1,2, \ldots} \\
& {[n]_{q}=n \quad \text { for } \quad q=1 .}
\end{aligned}
$$

For $q$ factorial and for $0 \leq k \leq n$, the $q$ binomials are defined as:

$$
[n]_{q} !=[n]_{q}[n-1]_{q} \cdots[1]_{q} \quad[0]_{q} !=1, \quad\left[\begin{array}{l}
n \\
k
\end{array}\right]_{q}=\frac{[n]_{q} !}{[k]_{q} ![n-k]_{q} !}
$$

Definition 1 (see [37]). The q-derivative for real valued continuous function $f(x)$ is defined as follows

$$
D_{q}(x)=\left(\frac{d}{d x}\right)_{q} f(x)=\frac{f(q x)-f(x)}{q x-x}, \quad q \neq 1 .
$$

When $q \rightarrow 1$, then the $q$-derivative is reduced to the standard derivative. Furthermore, the $q$-derivative can be represented as $\left(D_{q} f\right)(x)$, and it is known as the Jackson Derivative. The higher order q-derivative for the function $f(x)$ is given as

$$
D_{q}^{0} f=f, \quad D_{q}^{n} f=D_{q}\left(D_{q}^{n-1}\right) \quad \text { for } n=1,2,3, \ldots
$$

Definition 2 (see [37]). The q-derivative of product and quotient of function $f(x)$ and $g(x)$ is defined as follows

$$
\begin{aligned}
& D_{q}(f(x) g(x))=g(x) D_{q} f(x)+f(q x) D_{q} g(x)=g(q x) D_{q} f(x)+f(x) D_{q} g(x), \\
& D_{q}\left(\frac{f(x)}{g(x)}\right)=\frac{g(x) D_{q} f(x)-f(x) D_{q} g(x)}{g(q x) g(x)} \quad \text { such that } g(x) g(q x) \neq 0 .
\end{aligned}
$$

Definition 3 (see [30-32]). Let $f(x)$ be a continuous function on some interval $(a, b)$ and $c \in[a, b]$ then Jackson q-Taylor's formula is given as:

$$
f(x)=\sum_{k=1}^{\infty} \frac{D_{q}^{k}(x-c)^{k}}{[k] !} \quad(\forall x \in(a, b)),
$$


where,

$$
(x-c)^{0}=1, \quad(x-c)^{k}=\prod_{i=0}^{k-1}(x-c q)^{i}, \quad k \in N,
$$

where $0<q<1$ and $D_{q}, D_{q}^{2}, \ldots$ are all $q$-derivatives.

The rest of this article is organized as follows: in Section 2, the structures of the $q$ iterative methods will be designed by proposing the Lists A-C. In Section 3, we deal with the convergence analysis of the proposed $q$-iterative methods, and it is established that these methods have the same order of convergence as the classical methods for $q=1$. In Section 4, we present some of the examples to check the efficacy and performance of these methods. Furthermore, the comparisons of the results obtained by $q$-iterative methods with the previously known iterative methods will be discussed in the same section. Section 5 explores a general form of the $q$-iterative method based on the proposed iterative methods. Finally, the findings of our article are given in Section 6.

\section{Construction of the $q$-Iterative Methods}

In this section, some new different order multi-step $q$-iterative methods are constructed by considering the Taylor's series in the $q$-calculus. Here, we consider the nonlinear equation

$$
f(x)=0 \quad(\forall x \in R) .
$$

Suppose that $\alpha$ is the root of Equation (8) and $\lambda$ is an initial guess in the neighborhood of $\alpha$. By the same technique used in [28], we rewrite the nonlinear Equation (8) as the coupled system of equations by using the Taylor's series in the neighborhood of $\lambda$ in the q-calculus:

$$
\begin{aligned}
& f(\lambda)+(x-\lambda) D_{q} f(\lambda)+G(x)=0, \\
& G(x)=f(x)-f(\lambda)-(x-\lambda) D_{q} f(\lambda) .
\end{aligned}
$$

Since $f(x)=0$, the relation (10) can be written as:

$$
\begin{aligned}
& x=\lambda-\frac{f(\lambda)}{D_{q} f(\lambda)}-\frac{G(x)}{D_{q} f(\lambda)}, \\
& x=c+M_{q}(x),
\end{aligned}
$$

where

$$
c:=\lambda-\frac{f(\lambda)}{D_{q} f(\lambda)}
$$

and

$$
M_{q}(x):=-\frac{G(x)}{D_{q} f(\lambda)}
$$

is a nonlinear operator and $c$ is treated as constant.

It is noted that if we consider $x_{0}$ as an initial guess, then from (10), we have

$$
f\left(x_{0}\right)=G\left(x_{0}\right) .
$$

It is wort mentioning that Equation (15) plays a very significant role in the development of new multi-step $q$-iterative methods. Now, we establish a sequence of higher order iterative methods implementing the decomposition technique presented by Daftardar-Gejji 
and Jafari [18]. The main idea behind the implementation of this technique is to find out the solution of $q$-type functional Equation (12) in terms of infinite series:

$$
x=\sum_{i=0}^{\infty} x_{i}
$$

Now, we decompose the operator $M_{q}(x)$ defined in (14), such as:

$$
M_{q}(x)=M_{q}\left(x_{0}\right)+\sum_{i=1}^{\infty}\left\{M_{q}\left(\sum_{j=0}^{i} x_{j}\right)-M_{q}\left(\sum_{j=0}^{i-1} x_{j}\right)\right\} .
$$

From the Equations (12), (16) and (17), we have

$$
\sum_{i=1}^{\infty} x_{i}=c+M_{q}\left(x_{0}\right)+\sum_{i=1}^{\infty}\left\{M_{q}\left(\sum_{j=0}^{i} x_{j}\right)-M_{q}\left(\sum_{j=0}^{i-1} x_{j}\right)\right\},
$$

which generates the following iterative scheme

$$
\left\{\begin{aligned}
x_{0} & =c \\
x_{1} & =M_{q}\left(x_{0}\right), \\
x_{2} & =M_{q}\left(x_{0}+x_{1}\right)-M_{q}\left(x_{0}\right), \\
& \vdots \\
x_{n+1} & =M_{q}\left(\sum_{j=0}^{n} x_{j}\right)-M_{q}\left(\sum_{j=0}^{n-1} x_{j}\right), \quad n=1,2, \ldots
\end{aligned}\right.
$$

It follows that

$$
x_{1}+x_{2}+\cdots+x_{n+1}=M_{q}\left(x_{0}+x_{1}+x_{2}+\cdots+x_{n}\right),
$$

and

$$
x=c+\sum_{i=1}^{\infty} x_{i}
$$

Theorem 1 (see [34]). If $M$ is a contraction mapping, the defined series in (16) is absolutely convergent.

Proof. If $M$ is a contraction mapping, we see that

$$
\left\|M_{q}(x)-M_{q}(y)\right\| \leq \alpha\|x-y\| \quad 0<\alpha<1,
$$

then in view of (19), we have

$$
\begin{aligned}
& \left\|x_{n+1}\right\|=\left\|M_{q}\left(x_{1}+x_{2}+\ldots+x_{n}\right)-M_{q}\left(x_{1}+x_{2}+\ldots+x_{n-1}\right)\right\| \leq \alpha\left\|x_{n}\right\| \leq \alpha^{n}\left\|x_{0}\right\| \\
& n=0,1,2, \ldots
\end{aligned}
$$

So, the series $x=\sum_{i=0}^{\infty} x_{i}$ converges uniformly and absolutely to the solution of Equation (12) (see [38]). It is noted that $x$ is approximated by

$$
X_{n}=x_{0}+x_{1}+x_{2}+\cdots+x_{n}
$$

and thus $\lim _{x \rightarrow \infty} X_{n}=x$.

This completes the proof.

Our iterative techniques proceed with the following algorithms: 
List A: From (19), we have for $n=0$ :

$$
x \approx X_{0}=x_{0}=c=\lambda-\frac{f(\lambda)}{D_{q} f(\lambda)} .
$$

This formulation suggests the following iterative scheme for solving the nonlinear Equation (8). Now, for the given initial guess $x_{0}$, the approximate solution is computed by the iterative representation

$$
x_{n+1}=x_{n}-\frac{f\left(x_{n}\right)}{D_{q} f\left(x_{n}\right)}
$$

This represents the Newton's method in the $q$-calculus which has quadratic convergence. It is proved by Singh et al. [33].

By replacing the value of the $q$-derivative in (23), we have

$$
\begin{aligned}
x_{n+1} & =x_{n}-\frac{f\left(x_{n}\right)}{\frac{f\left(q x_{n}\right)-f\left(x_{n}\right)}{(q-1) x_{n}}} \\
& =x_{n}-\frac{(q-1) x_{n} f\left(x_{n}\right)}{f\left(q x_{n}\right)-f\left(x_{n}\right)}, \quad n=0,1, \ldots .
\end{aligned}
$$

This method resembles the method of secants (chords).

Now, with the help of (10) and (19), we get

$$
x_{1}=M_{q}\left(x_{0}\right)=-\frac{G\left(x_{0}\right)}{D_{q} f(\lambda)}=-\frac{f\left(x_{0}\right)}{D_{q} f(\lambda)} .
$$

List B: From (19), we have for $n=1$ :

$$
x \approx X_{1}=x_{0}+x_{1}=x_{0}+M_{q}\left(x_{0}\right) .
$$

By using (22) and (26), we have

$$
x=\lambda-\frac{f(\lambda)}{\left.D_{q} f(\lambda)\right)}-\frac{f\left(x_{0}\right)}{D_{q} f(\lambda)} .
$$

This formulation suggests the following iterative scheme for solving the nonlinear Equation (8).

For the given initial guess $x_{0}$, the approximate solution is computed by the following iterative method:

$$
\begin{aligned}
& y_{n}=x_{n}-\frac{f\left(x_{n}\right)}{D_{q} f\left(x_{n}\right)}, \\
& x_{n+1}=y_{n}-\frac{f\left(y_{n}\right)}{D_{q} f\left(x_{n}\right)}, \quad n=0,1,2, \ldots
\end{aligned}
$$

This is $q$-analogue of Chun method [3], which has cubic convergence for $q=1$. The error term for this algorithm is computed in Theorem (2). 
By using (10), (19) and (26), we can obtain

$$
\begin{aligned}
x_{1}+x_{2} & =M_{q}\left(x_{0}+x_{1}\right)=-\frac{G\left(x_{0}+x_{1}\right)}{D_{q} f(\lambda)} \\
& =-\frac{f\left(x_{0}+x_{1}\right)-f(\lambda)-\left(x_{0}+x_{1}-\lambda\right) D_{q} f(\lambda)}{D_{q} f(\lambda)} \\
& =-\frac{f\left(x_{0}+x_{1}\right)}{D_{q} f(\lambda)}-\frac{f\left(x_{0}\right)}{D_{q} f(\lambda)} .
\end{aligned}
$$

List C: Again, from (19), we have for $n=2$ :

$$
\begin{aligned}
x \approx X_{2} & =x_{0}+x_{1}+x_{2}=x_{0}+M_{q}\left(x_{0}\right)+M_{q}\left(x_{0}+x_{1}\right)-M_{q}\left(x_{0}\right) \\
& =c+M_{q}\left(x_{0}+x_{1}\right) .
\end{aligned}
$$

By using (22) and (31), we get

$$
x=\lambda-\frac{f(\lambda)}{D_{q} f(\lambda)}-\frac{f\left(x_{0}\right)}{D_{q} f(\lambda)}-\frac{f\left(x_{0}+x_{1}\right)}{D_{q} f(\lambda)} .
$$

This formulation allows us to suggest the following iterative method for solving the nonlinear Equation (8).

For the given initial guess $x_{0}$, the approximate solution is computed by the following iterative method:

$$
\begin{aligned}
& y_{n}=x_{n}-\frac{f\left(x_{n}\right)}{D_{q} f\left(x_{n}\right)}, \\
& z_{n}=y_{n}-\frac{f\left(y_{n}\right)}{D_{q} f\left(x_{n}\right)}, \\
& x_{n+1}=z_{n}-\frac{f\left(z_{n}\right)}{D_{q} f\left(x_{n}\right)}, \quad n=0,1,2, \ldots
\end{aligned}
$$

This is $q$-analogue of convergent iterative method was investigated by Ullah et al. [36]. Furthermore, it has fourth order convergence for $q=1$. The Error equation for this algorithm is computed in Theorem (2).

\section{Convergence Analysis}

This section is comprised of the convergence analysis of the $q$-iterative methods determined by Lists $\mathbf{B}$ and $\mathbf{C}$ in the previous section.

Theorem 2. Let $I \subset R$ be an open interval and $f: I \rightarrow R$ be a differentiable function. If $\alpha \in I$ is a simple root of $f(x)=0$ and $x_{0}$ is sufficiently close to $\alpha$, then the convergence order of multistep methods determined by Lists $\mathbf{B}$ and $\mathbf{C}$ have convergence of the order at least three and four, respectively, and we write it as $[3 ; q]$ and $[4 ; q]$, where $q$ represents $q$-calculus. Furthermore, it satisfies the error equations

$$
\begin{aligned}
& e_{n+1}=2 b_{2}^{2} e_{n}^{3}+\left(7 b_{2} b_{3}-9 b_{2}^{3}\right) e_{n}^{4}+O\left(e_{n}^{5}\right) \\
& e_{n+1}=4 b_{2}^{3} e_{n}^{4}+\left(20 b_{3} b_{2}^{2}-26 b_{2}^{4}\right) e_{n}^{5}+O\left(e_{n}^{6}\right) .
\end{aligned}
$$


Proof. Expanding $f\left(x_{n}\right)$ and $D_{q} f\left(x_{n}\right)$ in terms of $q$-Taylor's series about $\alpha$ to get

$$
\begin{aligned}
& f\left(x_{n}\right)=D_{q} f(\alpha) e_{n}+\frac{1}{[2] !} D_{q}^{2} f(\alpha) e_{n}^{2}+\frac{1}{[3] !} D_{q}^{3} f(\alpha) e_{n}^{3}+\cdots, \\
& f\left(x_{n}\right)=D_{q} f(\alpha)\left\{e_{n}+b_{2} e_{n}^{2}+b_{3} e_{n}^{3}+b_{4} e_{n}^{4}+\cdots\right\}, \\
& D_{q} f\left(x_{n}\right)=D_{q} f(\alpha)\left\{1+2 b_{2} e_{n}+3 b_{3} e_{n}^{2}+4 b_{4} e_{n}^{3}+\cdots\right\},
\end{aligned}
$$

where

$$
b_{m}=\frac{D_{q}^{m} f(\alpha)}{[m] ! D_{q} f(\alpha)} \quad \text { for } m=2,3, \ldots \quad \text { and } \quad e_{n}=x_{n}-\alpha .
$$

In view of the Equations (38) and (39), we get

$$
\frac{f\left(x_{n}\right)}{D_{q} f\left(x_{n}\right)}=e_{n}-b_{2} e_{n}^{2}-\left(2 b_{3}-2 b_{2}^{2}\right) e_{n}^{3}+O\left(e_{n}^{4}\right) .
$$

Now, by substituting (41) into (29), we get

$$
y_{n}=x_{n}-\frac{f_{q}\left(x_{n}\right)}{D_{q} f\left(x_{n}\right)}=\alpha+b_{2} e_{n}^{2}+\left(2 b_{3}-2 b_{2}^{2}\right) e_{n}^{3}+O\left(e_{n}^{4}\right) .
$$

Expanding $f\left(y_{n}\right)$ in terms of Taylor's series about $\alpha$ to get

$$
f\left(y_{n}\right)=D_{q} f(\alpha)\left\{b_{2} e_{n}^{2}+\left(2 b_{3}-2 b_{2}^{2}\right) e_{n}^{3}+\left(3 b_{4}-7 b_{2} b_{3}+5 b_{2}^{3}\right) e_{n}^{4}+O\left(e_{n}^{5}\right)\right\} .
$$

From (39) and (43), we have

$$
\frac{f\left(y_{n}\right)}{D_{q} f\left(x_{n}\right)}=b_{2} e_{n}^{2}+\left(2 b_{3}-4 b_{2}^{2}\right) e_{n}^{3}+\left(3 b_{4}-14 b_{2} b_{3}+13 b_{2}^{3}\right) e_{n}^{4}+O\left(e_{n}^{5}\right) .
$$

By applying (42) and (44) into (30), we get the error term of the List B:

$$
\begin{aligned}
x_{n+1} & =\alpha+2 b_{2}^{2} e_{n}^{3}+\left(7 b_{2} b_{3}-9 b_{2}^{3}\right) e_{n}^{4}+O\left(e_{n}^{5}\right) \\
e_{n+1} & =2 b_{2}^{2} e_{n}^{3}+\left(7 b_{2} b_{3}-9 b_{2}^{3}\right) e_{n}^{4}+O\left(e_{n}^{5}\right) \\
z_{n} & =\alpha+2 b_{2}^{2} e_{n}^{3}+\left(7 b_{2} b_{3}-9 b_{2}^{3}\right) e_{n}^{4}+O\left(e_{n}^{5}\right) .
\end{aligned}
$$

Expanding $f\left(z_{n}\right)$ in terms of Taylor's series about $\alpha$ to get

$$
\begin{aligned}
f\left(z_{n}\right)=D_{q} f(\alpha)\left\{2 b_{2}^{2} e_{n}^{3}+\left(7 b_{2} b_{3}\right.\right. & \left.-9 b_{2}^{3}\right) e_{n}^{4} \\
& \left.+\left(10 b_{2} b_{4}+6 c_{3}^{2}-44 b_{3} b_{2}^{2}+30 b_{2}^{4}\right) e_{n}^{5}+O\left(e_{n}^{6}\right)\right\} .
\end{aligned}
$$

By the help of (39) and (46), we can deduce

$$
\begin{aligned}
\frac{f\left(z_{n}\right)}{D_{q} f\left(x_{n}\right)}=2 b_{2}^{2} e_{n}^{3}+\left(7 b_{2} b_{3}-13 b_{2}^{3}\right) & e_{n}^{4} \\
& +\left(10 b_{2} b_{4}+6 b_{3}^{2}-64 b_{3} b_{2}^{2}+56 b_{2}^{4}\right) e_{n}^{5}+O\left(e_{n}^{6}\right) .
\end{aligned}
$$


By applying (45) and (47) into (34), we get the error term of the List C:

$$
\begin{gathered}
x_{n+1}=\alpha+4 b_{2}^{3} e_{n}^{4}+\left(20 b_{3} b_{2}^{2}-26 b_{2}^{4}\right) e_{n}^{5}+O\left(e_{n}^{6}\right), \\
e_{n+1}=4 b_{2}^{3} e_{n}^{4}+\left(20 b_{3} b_{2}^{2}-26 b_{2}^{4}\right) e_{n}^{5}+O\left(e_{n}^{6}\right) .
\end{gathered}
$$

This completes the proof.

\section{Numerical Examples and Comparison Results}

This section elaborates on the efficacy of algorithms introduced in this paper with the support of examples. All the numerical experiments are performed with Intel (R) Core [TM] $2 \times 2.1 \mathrm{GHz}, 12 \mathrm{~GB}$ of RAM, and all the codes are written in Maple. We use $\varepsilon=10^{-15}$ and obtain an approximated simple root rather than the exact based on the exactness $\varepsilon$ of the computer.

For the computational work, we use the following stopping criteria:

$$
\text { (i) }\left|x_{n+1}-x_{n}\right|<\varepsilon \quad \text { and } \quad(i i)\left|f\left(x_{n+1}\right)\right|<\varepsilon
$$

Abbreviation CAG is used for classical iterative method and QAG for the $q$-analogue of classical iterative method, and term div is used for divergence of method.

Recall the classical List 2.2 in [35] (CAG1), defined by

$$
y_{n}=x_{n}-\frac{f\left(x_{n}\right)}{f^{\prime}\left(x_{n}\right)} \quad \text { and } \quad x_{n+1}=y_{n}-\frac{f\left(y_{n}\right)}{f^{\prime}\left(x_{n}\right)} \quad(\forall n=0,1,2, \ldots) .
$$

and the classical List 2.3 in [36] (CAG2), defined by

$$
\begin{aligned}
& y_{n}=x_{n}-\frac{f\left(x_{n}\right)}{f^{\prime}\left(x_{n}\right)} \\
& z_{n}=y_{n}-\frac{f\left(y_{n}\right)}{f^{\prime}\left(x_{n}\right)} \\
& x_{n+1}=z_{n}-\frac{f\left(z_{n}\right)}{f^{\prime}\left(x_{n}\right)}, \quad \text { for } n=0,1,2, \ldots
\end{aligned}
$$

For simplicity, we denote the iterative Lists B and C by QAG1 and QAG2, respectively. The computational results are presented in Tables 1-6 to elaborate the performance and efficacy of our $q$ iterative methods that is the main motivation of transformation of the classical methods towards the $q$-iterative methods.

For simplicity, initially in Examples 1-3, we check the performance of $q$-iterative methods with the classical methods for different values of $q$ up to three iterations. Similarly, we can check the performance of the $q$-iterative methods for the different values of $q$ for the rest of the iterations until we achieve the desired accuracy.

Example 1 (see [3]). We consider the nonlinear equation:

$$
f(x)=x e^{x^{2}}-\sin ^{2} x+3 \cos x+5 .
$$

The exact solution for this example is $x=1.207647827130919$. We take $x_{0}=-2$ as an initial guess. Table 1 shows the computation of $x_{i}$ and $f\left(x_{i}\right)$ for $i=1,2,3$ and different values of $q$ by using QAG1. 
Table 1. Calculation of $x_{i}$ and $f\left(x_{i}\right)$ for $i=1,2,3$ and different values of $q$ by using QAG1.

\begin{tabular}{ccccccc}
\hline$q$ & $x_{1}$ & $f\left(x_{1}\right)$ & $x_{\mathbf{2}}$ & $f\left(x_{\mathbf{2}}\right)$ & $x_{3}$ & $f\left(x_{\mathbf{3}}\right)$ \\
\hline 1.02 & 1.7250206931 & $3.025329 \mathrm{e}+01$ & 1.4474835253 & $7.379764 \mathrm{e}+00$ & 1.2518646781 & $9.612675 \mathrm{e}-01$ \\
\hline 1.01 & 1.7146118692 & $2.883931 \mathrm{e}+01$ & 1.4305859139 & $6.635881 \mathrm{e}+00$ & 1.2420681659 & $7.368529 \mathrm{e}-01$ \\
\hline 0.9999 & 1.7039972727 & $2.746138 \mathrm{e}+01$ & 1.4138444432 & $5.942719 \mathrm{e}+00$ & 1.2336242968 & $5.488326 \mathrm{e}-01$ \\
\hline 0.98 & 1.6827973761 & $2.489016 \mathrm{e}+01$ & 1.3819710496 & $4.732768 \mathrm{e}+00$ & 1.2210048207 & $2.767866 \mathrm{e}-01$ \\
\hline 0.97 & 1.6720053179 & $2.366777 \mathrm{e}+01$ & 1.3665877297 & $4.195734 \mathrm{e}+00$ & 1.2164975903 & $1.821333 \mathrm{e}-01$ \\
\hline 0.99 & 1.6934971518 & $2.615875 \mathrm{e}+01$ & 1.3977906174 & $5.316156 \mathrm{e}+00$ & 1.2267061933 & $3.983936 \mathrm{e}-01$ \\
\hline 0.96 & 1.6611219970 & $2.249026 \mathrm{e}+01$ & 1.3516779288 & $3.701888 \mathrm{e}+00$ & 1.2130682867 & $1.109783 \mathrm{e}-01$ \\
\hline 0.95 & 1.6501477370 & $2.135624 \mathrm{e}+01$ & 1.3372782267 & $3.248313 \mathrm{e}+00$ & 1.2105873872 & $5.995948 \mathrm{e}-02$ \\
\hline 0.9 & 1.5938858602 & $1.628822 \mathrm{e}+01$ & 1.2741571956 & $1.498487 \mathrm{e}+00$ & 1.2074940697 & $3.121695 \mathrm{e}-03$ \\
\hline 0.8 & 1.4737314129 & $8.631573 \mathrm{e}+00$ & 1.2037818654 & $7.805411 \mathrm{e}-02$ & 1.2070782899 & $1.155594 \mathrm{e}-02$ \\
\hline 0.7 & 1.3426598641 & $3.415231 \mathrm{e}+00$ & 1.2098745341 & $4.537035 \mathrm{e}-02$ & 1.2083400493 & $1.407187 \mathrm{e}-02$ \\
\hline 0.6 & 1.2021358529 & $1.110139 \mathrm{e}-01$ & 1.2043272420 & $6.709762 \mathrm{e}-02$ & 1.2056858306 & $3.972595 \mathrm{e}-02$ \\
\hline 0.5 & 1.0551639918 & $2.509831 \mathrm{e}+00$ & 0.8000270036 & $5.058134 \mathrm{e}+00$ & 5.3921025287 & $2.284390 \mathrm{e}+13$ \\
\hline 0.4 & 1.2618215234 & $1.196531 \mathrm{e}+00$ & 1.2449990477 & $8.032748 \mathrm{e}-01$ & 1.2395189569 & $6.795706 \mathrm{e}-01$ \\
\hline
\end{tabular}

Proceeding in the way of Table 1, we get $x=1.2076478271$ for different values of $q$, which is the required solution. One can observe from Table 1 that more accurate values of $x_{i}$ s can be obtained when $q$ approaches towards one and for which $f\left(x_{i}\right)$ tend towards zero. The values of $f\left(x_{1}\right)=2.746138 \mathrm{e}+01, f\left(x_{2}\right)=5.942719 \mathrm{e}+00, f\left(x_{3}\right)=5.488326 \mathrm{e}-$ 01 calculated by QAG1 at $q=0.9999$ are closer to zero as compared to the values $f\left(x_{1}\right)$ $=2.747477 \mathrm{e}+01, f\left(x_{2}\right)=5.949309 \mathrm{e}+00, f\left(x_{3}\right)=5.505169 \mathrm{e}-01$ calculated by CAG1 Furthermore, Equation (51) converges towards the root $x_{5}=1.2076478271$ for $q=0.9999$ and $f(x)=4.435401 \mathrm{e}-12$. Table 2 shows the computation of $x_{i}$ and $f\left(x_{i}\right)$ for $i=1,2,3$ for different values of $q$ by using the List C (QAG2).

Table 2. Calculation of $x_{i}$ and $f\left(x_{i}\right)$ for $i=1,2,3$ and different values of $q$ by using QAG2.

\begin{tabular}{ccccccc}
\hline$q$ & $x_{1}$ & $f\left(x_{1}\right)$ & $x_{2}$ & $f\left(x_{2}\right)$ & $x_{3}$ & $f\left(x_{3}\right)$ \\
\hline 1.02 & 1.6694991316 & $2.339181 \mathrm{e}+01$ & 1.3531960626 & $3.751021 \mathrm{e}+00$ & 1.2127490200 & $1.043912 \mathrm{e}-01$ \\
\hline 1.01 & 1.6589604001 & $2.226275 \mathrm{e}+01$ & 1.3391400100 & $3.305714 \mathrm{e}+00$ & 1.2107771567 & $6.384855 \mathrm{e}-02$ \\
\hline 0.9999 & 1.6483076255 & $2.117115 \mathrm{e}+01$ & 1.3256085221 & $2.896627 \mathrm{e}+00$ & 1.2094270195 & $3.622758 \mathrm{e}-02$ \\
\hline 0.99 & 1.6378605159 & $2.014678 \mathrm{e}+01$ & 1.3130192725 & $2.532342 \mathrm{e}+00$ & 1.2085807901 & $1.897265 \mathrm{e}-02$ \\
\hline 0.98 & 1.6273047549 & $1.915594 \mathrm{e}+01$ & 1.3010027394 & $2.198535 \mathrm{e}+00$ & 1.2080737484 & $8.654896 \mathrm{e}-03$ \\
\hline 0.97 & 1.6167470984 & $1.820720 \mathrm{e}+01$ & 1.2897082127 & $1.896564 \mathrm{e}+00$ & 1.2078048652 & $3.189788 \mathrm{e}-03$ \\
\hline 0.96 & 1.6061879189 & $1.729859 \mathrm{e}+01$ & 1.2791506509 & $1.624142 \mathrm{e}+00$ & 1.2076848052 & $7.509703 \mathrm{e}-04$ \\
\hline 0.95 & 1.5956267820 & $1.642815 \mathrm{e}+01$ & 1.2693411891 & $1.379186 \mathrm{e}+00$ & 1.2076465297 & $2.634743 \mathrm{e}-05$ \\
\hline 0.9 & 1.5427300899 & $1.258434 \mathrm{e}+01$ & 1.2316217651 & $5.049568 \mathrm{e}-01$ & 1.2076068661 & $8.317613 \mathrm{e}-04$ \\
\hline 0.8 & 1.4351491676 & $6.832250 \mathrm{e}+00$ & 1.2061294870 & $3.076338 \mathrm{e}-02$ & 1.2077295521 & $1.659826 \mathrm{e}-03$ \\
\hline 0.7 & 1.3223454750 & $2.800732 \mathrm{e}+00$ & 1.2066348770 & $2.053914 \mathrm{e}-02$ & 1.2078327767 & $3.756890 \mathrm{e}-03$ \\
\hline 0.6 & 1.2029703471 & $9.432425 \mathrm{e}-02$ & 1.2097943109 & $4.373048 \mathrm{e}-02$ & 1.2067390111 & $1.843054 \mathrm{e}-02$ \\
\hline 0.5 & 1.0780919174 & $2.195871 \mathrm{e}+00$ & 1.4172230345 & $6.079244 \mathrm{e}+00$ & 1.2081162362 & $9.518872 \mathrm{e}-03$ \\
\hline 0.4 & 0.9495337533 & $3.745734 \mathrm{e}+00$ & 0.5641997450 & $6.473432 \mathrm{e}+00$ & div & div \\
\hline
\end{tabular}


Proceeding in the way of Table 2, we get the required solution $x=1.2076478271$. From Table 2, we see that if $q$ approaches one, we can obtain more accurate values of $x_{i}$ s for which $f\left(x_{i}\right)$ s tends towards zero, where $i=1,2,3$. It is also observe that the values of $f\left(x_{1}\right)=2.117115 \mathrm{e}+01, f\left(x_{2}\right)=2.896627 \mathrm{e}+00, f\left(x_{3}\right)=3.622758 \mathrm{e}-02$ at $q=0.9999 \mathrm{calcu}-$ lated by QAG2 are closer to zero as compared to the values of $f\left(x_{1}\right)=2.118172 \mathrm{e}+01, f\left(x_{2}\right)$ $=2.900487 \mathrm{e}+00, f\left(x_{3}\right)=3.644647 \mathrm{e}-02$ calculated by CAG2. Furthermore, Equation (51) converges to the root $x_{5}=1.2076478271$ for $q=0.9999$ and $f(x)=1.424874 \mathrm{e}-20$.

Example 2 (see [39] (Population growth model)). Consider the nonlinear equation

$$
1564000=1000000 e^{\lambda}+\frac{435000}{\lambda}\left(e^{\lambda}-1\right) .
$$

This equation appears in the mathematical modeling of the growth of population over short periods of time, where $\lambda$ denotes the constant birth rate of population whose value needs to determined.

For computational work, we take $x_{0}=1.5$ as an initial estimate. The solution of this example approximated to 16 decimal digits is 0.1009979296857498 . In Table 3, we compute the values of $x_{1}, x_{2}, x_{3}$ and $f\left(x_{1}\right), f\left(x_{2}\right), f\left(x_{3}\right)$ for different values of $q$ by using QAG1.

Table 3. The computed values of $x_{i}$ and $f\left(x_{i}\right)$ for $i=1,2,3$ and different values of $q$ by using QAG1.

\begin{tabular}{ccccccc}
\hline$q$ & $x_{1}$ & $f\left(x_{1}\right)$ & $x_{2}$ & $f\left(x_{2}\right)$ & $x_{3}$ & $f\left(x_{3}\right)$ \\
\hline 1.02 & 0.5142791696 & $6.772056 \mathrm{e}+05$ & 0.1232018298 & $3.004429 \mathrm{e}+04$ & 0.1010035073 & $7.468324 \mathrm{e}+00$ \\
\hline 1.01 & 0.5097137812 & $6.681808 \mathrm{e}+05$ & 0.1222121457 & $2.869170 \mathrm{e}+04$ & 0.1010024505 & $6.053356 \mathrm{e}+00$ \\
\hline 0.9999 & 0.5051056237 & $6.591112 \mathrm{e}+05$ & 0.1212441701 & $2.736999 \mathrm{e}+04$ & 0.1010015437 & $4.839200 \mathrm{e}+00$ \\
\hline 0.99 & 0.5005916534 & $6.502654 \mathrm{e}+05$ & 0.1203256645 & $2.611695 \mathrm{e}+04$ & 0.1010007932 & $3.834194 \mathrm{e}+00$ \\
\hline 0.98 & 0.4960351599 & $6.413748 \mathrm{e}+05$ & 0.1194278075 & $2.489313 \mathrm{e}+04$ & 0.1010001573 & $2.982748 \mathrm{e}+00$ \\
\hline 0.97 & 0.4914818733 & $6.325288 \mathrm{e}+05$ & 0.1185594952 & $2.371057 \mathrm{e}+04$ & 0.1009996292 & $2.275633 \mathrm{e}+00$ \\
\hline 0.96 & 0.4869319106 & $6.237276 \mathrm{e}+05$ & 0.1177201915 & $2.256843 \mathrm{e}+04$ & 0.1009991952 & $1.694573 \mathrm{e}+00$ \\
\hline 0.95 & 0.4823853861 & $6.149710 \mathrm{e}+05$ & 0.1169093583 & $2.146590 \mathrm{e}+04$ & 0.1009988432 & $1.223128 \mathrm{e}+00$ \\
\hline 0.9 & 0.4597081677 & $5.718559 \mathrm{e}+05$ & 0.1132633228 & $1.651858 \mathrm{e}+04$ & 0.1009979633 & $4.506777 \mathrm{e}-02$ \\
\hline 0.8 & 0.4146701230 & $4.889359 \mathrm{e}+05$ & 0.1077950521 & $9.130505 \mathrm{e}+03$ & 0.1009981060 & $2.360760 \mathrm{e}-01$ \\
\hline 0.7 & 0.3701214518 & $4.103351 \mathrm{e}+05$ & 0.1043132261 & $4.446092 \mathrm{e}+03$ & 0.1009984405 & $6.839589 \mathrm{e}-01$ \\
\hline 0.6 & 0.3261190990 & $3.358939 \mathrm{e}+05$ & 0.1023101377 & $1.758120 \mathrm{e}+03$ & 0.1009983768 & $5.987359 \mathrm{e}-01$ \\
\hline 0.5 & 0.2826923050 & $2.654100 \mathrm{e}+05$ & 0.1013283547 & $4.425044 \mathrm{e}+02$ & 0.1009981173 & $2.511882 \mathrm{e}-01$ \\
\hline 0.4 & 0.2398433266 & $1.986490 \mathrm{e}+05$ & 0.1009777753 & $2.698620 \mathrm{e}+01$ & 0.1009979129 & $2.244417 \mathrm{e}-02$ \\
\hline
\end{tabular}

Proceeding as the way of Table 3 , we get the required solution $x=0.1009979296857498$. From Table 3, It can easily observe that we obtain more accurate values of $x_{1}, x_{2}, x_{3}$ when $q$ approaches one and for which $f\left(x_{1}\right), f\left(x_{2}\right), f\left(x_{3}\right)$ tend towards zero. The values of $f\left(x_{1}\right)=6.591112 e+05$, $f\left(x_{2}\right)=2.736999 e+04, f\left(x_{3}\right)=4.839200 e+00$ at $q=0.9999$ computed by QAG1 are closer to zero as compared to the other values of $f\left(x_{1}\right)=6.592007 e+05, f\left(x_{2}\right)=2.738286 e+04$, $f\left(x_{3}\right)=4.850247 e+00$ computed by CAG1. Furthermore, Equation (52) converges towards the root $x_{5}=0.1009979297$ in the fifth iteration for $q=0.9999$ and $f\left(x_{5}\right)=4.545278 \mathrm{e}-22$.

Meantime, in Table 4, we compute the values of $x_{1}, x_{2}, x_{3}$ and $f\left(x_{1}\right), f\left(x_{2}\right), f\left(x_{3}\right)$ for different values of $q$ by using QAG2. 
Table 4. The computed values of $x_{i}$ and $f\left(x_{i}\right)$ for $i=1,2,3$ and different values of $q$ by using QAG2.

\begin{tabular}{ccccccc}
\hline$q$ & $x_{1}$ & $f\left(x_{1}\right)$ & $x_{2}$ & $f\left(x_{\mathbf{2}}\right)$ & $x_{3}$ & $f\left(x_{3}\right)$ \\
\hline 1.02 & 0.3836245813 & $4.338095 \mathrm{e}+05$ & 0.1028722679 & $2.511938 \mathrm{e}+03$ & 0.1009979297 & $3.473304 \mathrm{e}-05$ \\
\hline 1.01 & 0.3798572173 & $4.272299 \mathrm{e}+05$ & 0.1027414335 & $2.336453 \mathrm{e}+03$ & 0.1009979297 & $1.377622 \mathrm{e}-05$ \\
\hline 0.9999 & 0.3760675536 & $4.206350 \mathrm{e}+05$ & 0.1026168764 & $2.169407 \mathrm{e}+03$ & 0.1009979297 & $3.799508 \mathrm{e}-06$ \\
\hline 0.99 & 0.3723680428 & $4.142198 \mathrm{e}+05$ & 0.1025018597 & $2.015174 \mathrm{e}+03$ & 0.1009979297 & $3.969817 \mathrm{e}-07$ \\
\hline 0.98 & 0.3686464634 & $4.077891 \mathrm{e}+05$ & 0.1023924737 & $1.868507 \mathrm{e}+03$ & 0.1009979297 & $7.033782 \mathrm{e}-08$ \\
\hline 0.97 & 0.3649403724 & $4.014077 \mathrm{e}+05$ & 0.1022896062 & $1.730594 \mathrm{e}+03$ & 0.1009979297 & $7.550798 \mathrm{e}-08$ \\
\hline 0.96 & 0.3612498787 & $3.950754 \mathrm{e}+05$ & 0.1021929573 & $1.601031 \mathrm{e}+03$ & 0.1009979297 & $1.396345 \mathrm{e}-06$ \\
\hline 0.95 & 0.3575750888 & $3.887920 \mathrm{e}+05$ & 0.1021022363 & $1.479425 \mathrm{e}+03$ & 0.1009979297 & $5.200839 \mathrm{e}-06$ \\
\hline 0.9 & 0.3394402376 & $3.581029 \mathrm{e}+05$ & 0.1017280112 & $9.779077 \mathrm{e}+02$ & 0.1009979296 & $7.367781 \mathrm{e}-05$ \\
\hline 0.8 & 0.3044020340 & $3.002834 \mathrm{e}+05$ & 0.1012821950 & $3.806792 \mathrm{e}+02$ & 0.1009979295 & $3.115139 \mathrm{e}-04$ \\
\hline 0.7 & 0.2710667500 & $2.470282 \mathrm{e}+05$ & 0.1010864659 & $1.185540 \mathrm{e}+02$ & 0.1009979294 & $3.461354 \mathrm{e}-04$ \\
\hline 0.6 & 0.2394852751 & $1.981025 \mathrm{e}+05$ & 0.1010160263 & $2.423142 \mathrm{e}+01$ & 0.1009979296 & $1.702203 \mathrm{e}-04$ \\
\hline 0.5 & 0.2096843622 & $1.532571 \mathrm{e}+05$ & 0.1009984548 & $7.031754 \mathrm{e}-01$ & 0.1009979297 & $9.707395 \mathrm{e}-06$ \\
\hline
\end{tabular}

We can observe from Table 4 that we get more accurate values of $x_{1}, x_{2}, x_{3}$ when $q$ approaches one and for which $f\left(x_{1}\right), f\left(x_{2}\right), f\left(x_{3}\right)$ tend towards zero. In addition, the values of $f\left(x_{1}\right)=4.206350 e+05, f\left(x_{2}\right)=2.169407 e+03, f\left(x_{3}\right)=3.799508 e-06$ calculated by QAG2 at $q=0.9999$ are closer to zero as compared to the values $f\left(x_{1}\right)=4.207000 e+05$, $f\left(x_{2}\right)=2.171013 e+03, f\left(x_{3}\right)=3.859455 e-06$ calculated by CAG2. Furthermore, Equation (52) converges towards the root $x_{4}=0.1009979296857498$ in the fourth iteration for $q=0.9999$ and $f(x)=4.103556 e-22$.

Example 3 (see [40]). Consider the van der Waal's equation

$$
f(x)=0.986 x^{3}-5.181 x^{2}+9.067 x-5.289 .
$$

This equation is used to interpret the real and ideal gas behavior that has been converted to the non-linear form after choosing the appropriate values of the parameters. Its exact solution is $x=1.92984624284786221849$. Here, we take $x_{0}=3.10$.

Table 5. The calculated values of $x_{i}$ and $f\left(x_{i}\right)$ for $i=1,2,3$ and different values of $q$ by using QAG1.

\begin{tabular}{ccccccc}
\hline $\boldsymbol{q}$ & $x_{\mathbf{1}}$ & $f\left(x_{\mathbf{1}}\right)$ & $x_{\mathbf{2}}$ & $f\left(x_{\mathbf{2}}\right)$ & $x_{3}$ & $f\left(x_{3}\right)$ \\
\hline 0.9999 & 2.5202589147 & $4.378340 \mathrm{e}-01$ & 2.1949546968 & $7.835843 \mathrm{e}-02$ & 2.0201748257 & $1.283785 \mathrm{e}-02$ \\
\hline 0.99 & 2.5115105320 & $4.227815 \mathrm{e}-01$ & 2.1831373107 & $7.175670 \mathrm{e}-02$ & 2.0087578377 & $1.058966 \mathrm{e}-02$ \\
\hline 0.98 & 2.5025058715 & $4.076474 \mathrm{e}-01$ & 2.1709804383 & $6.533731 \mathrm{e}-02$ & 1.9971609647 & $8.509070 \mathrm{e}-03$ \\
\hline 0.97 & 2.4933259775 & $3.925895 \mathrm{e}-01$ & 2.1585882787 & $5.917107 \mathrm{e}-02$ & 1.9855208132 & $6.617240 \mathrm{e}-03$ \\
\hline 0.95 & 2.4744109780 & $3.627241 \mathrm{e}-01$ & 2.1330269816 & $4.760752 \mathrm{e}-02$ & 1.9622425575 & $3.387207 \mathrm{e}-03$ \\
\hline 0.9 & 2.4234483030 & $2.897601 \mathrm{e}-01$ & 2.0632626947 & $2.326221 \mathrm{e}-02$ & 1.9080108794 & $1.646041 \mathrm{e}-03$ \\
\hline 0.8 & 2.2993595203 & $1.537076 \mathrm{e}-01$ & 1.8634563691 & $3.701777 \mathrm{e}-03$ & 1.9049539739 & $1.839852 \mathrm{e}-03$ \\
\hline 0.7 & 2.1233417817 & $4.361666 \mathrm{e}-02$ & 1.7302041526 & $4.077219 \mathrm{e}-03$ & 1.7584545862 & $4.282942 \mathrm{e}-03$ \\
\hline 0.6 & 1.8638867517 & $3.689049 \mathrm{e}-03$ & 1.8851091208 & $2.899285 \mathrm{e}-03$ & 1.9024486639 & $1.992358 \mathrm{e}-03$ \\
\hline 0.5 & 1.5633390425 & $9.364898 \mathrm{e}-03$ & 1.5791722007 & $7.962836 \mathrm{e}-03$ & 1.5931768979 & $1.567623 \mathrm{e}-03$ \\
\hline 0.4 & 1.3893319818 & $4.831340 \mathrm{e}-02$ & 1.4342000910 & $3.331323 \mathrm{e}-02$ & 1.4679207997 & $2.455640 \mathrm{e}-02$ \\
\hline
\end{tabular}


By proceeding as the above table, we can obtain the required solution $x=1.9298462428$. From Table 5, we can observe that we get more accurate values of $x_{1}, x_{2}, x_{3}$ for which $f\left(x_{1}\right), f\left(x_{2}\right)$, $f\left(x_{3}\right)$ tend towards zero when $q$ approaches one. The values of $f\left(x_{1}\right)=4.378340 e-01$, $f\left(x_{2}\right)=7.835843 e-02, f\left(x_{3}\right)=1.283785 e-02$ at $q=0.9999$ computed by QAG1 are closer to zero as compared to the values of $f\left(x_{1}\right)=4.379863 e-01, f\left(x_{2}\right)=7.842636 e-0$, $f\left(x_{3}\right)=1.286153 e-02$ computed by CAG1. Furthermore, Equation (53) converges towards the root $x_{7}=1.92984624284786221850$ in the seventh iteration for $q=0.9999$ and $f(x)=3.081547 e-18$.

Table 6. The calculated values of $x_{i}$ and $f\left(x_{i}\right)$ for $i=1,2,3$ and different values of $q$ by using QAG2.

\begin{tabular}{ccccccc}
\hline$q$ & $x_{1}$ & $f\left(x_{1}\right)$ & $x_{2}$ & $f\left(x_{2}\right)$ & $x_{3}$ & $f\left(x_{3}\right)$ \\
\hline 1.02 & 2.4541906439 & $3.324888 \mathrm{e}-01$ & 2.1294971623 & $4.612880 \mathrm{e}-02$ & 1.9793132558 & $5.685628 \mathrm{e}-03$ \\
\hline 1.01 & 2.4465460254 & $3.215032 \mathrm{e}-01$ & 2.1199949026 & $4.228580 \mathrm{e}-02$ & 1.9716511617 & $4.607177 \mathrm{e}-03$ \\
\hline 0.9999 & 2.4387247327 & $3.105124 \mathrm{e}-01$ & 2.1103029536 & $3.856881 \mathrm{e}-02$ & 1.9641322014 & $3.623214 \mathrm{e}-03$ \\
\hline 0.99 & 2.4309573266 & $2.998435 \mathrm{e}-01$ & 2.1007067436 & $3.508499 \mathrm{e}-02$ & 1.9570428610 & $2.760648 \mathrm{e}-03$ \\
\hline 0.98 & 2.4230062579 & $2.891735 \mathrm{e}-01$ & 2.0909118772 & $3.172520 \mathrm{e}-02$ & 1.9502501877 & $1.991531 \mathrm{e}-03$ \\
\hline 0.97 & 2.4149452314 & $2.786122 \mathrm{e}-01$ & 2.0810081426 & $2.852389 \mathrm{e}-02$ & 1.9439396580 & $1.325652 \mathrm{e}-03$ \\
\hline 0.96 & 2.4067694211 & $2.681611 \mathrm{e}-01$ & 2.0709868209 & $2.547916 \mathrm{e}-02$ & 1.9382576782 & $7.649241 \mathrm{e}-04$ \\
\hline 0.95 & 2.3984733326 & $2.578211 \mathrm{e}-01$ & 2.0608364625 & $2.258868 \mathrm{e}-02$ & 1.9333949804 & $3.134112 \mathrm{e}-04$ \\
\hline 0.9 & 2.3549374981 & $2.077991 \mathrm{e}-01$ & 2.0074163967 & $1.033870 \mathrm{e}-02$ & 1.9308693710 & $8.898415 \mathrm{e}-05$ \\
\hline 0.8 & 2.2524565779 & $1.158895 \mathrm{e}-01$ & 1.8514430978 & $4.009256 \mathrm{e}-03$ & 1.9336672846 & $3.380165 \mathrm{e}-04$ \\
\hline 0.7 & 2.1059949469 & $3.698096 \mathrm{e}-02$ & 1.8046133598 & $4.487988 \mathrm{e}-03$ & 1.8679147777 & $3.563896 \mathrm{e}-03$ \\
\hline 0.6 & 1.8657872051 & $3.631368 \mathrm{e}-03$ & 1.8953688005 & $2.393342 \mathrm{e}-03$ & 1.9150164412 & $1.168978 \mathrm{e}-03$ \\
\hline 0.5 & 1.5693521850 & $8.800824 \mathrm{e}-03$ & 1.5911971423 & $7.070040 \mathrm{e}-03$ & 1.6098711773 & $5.951690 \mathrm{e}-03$ \\
\hline 0.4 & 1.4247737346 & $3.613315 \mathrm{e}-02$ & 1.4748490103 & $2.300092 \mathrm{e}-02$ & 1.5105345877 & $1.619046 \mathrm{e}-02$ \\
\hline
\end{tabular}

The computational results obtained from Table 6 illustrate the accuracy of the values of $x_{1}, x_{2}, x_{3}$ when $q$ approaches one and for which $f\left(x_{1}\right), f\left(x_{2}\right), f\left(x_{3}\right)$ tend towards zero. Moreover, the values of $f\left(x_{1}\right)=3.105124 e-01, f\left(x_{2}\right)=3.856881 e-02, f\left(x_{3}\right)=3.623214 e-03$ at $q=0.9999$ computed by QAG2, are closer to zero as compared to $f\left(x_{1}\right)=3.106207 e-01$, $f\left(x_{2}\right)=3.860481$ e $-02, f\left(x_{3}\right)=3.632441$ e -03 computed by CAG2. Furthermore, Equation (53) converges towards the root $x_{6}=1.92984624284786221849$ in the sixth iteration for $q=0.9999$ and $f(x)=2.935505 e-21$.

\subsection{Error Analysis and Application of the q-Iterative Methods}

Error is considered as the difference between a true value and an estimate (see [39]), or an approximation, it can easily be observed from the numerical values that if we compute the errors of $q$-iterative methods than they fluctuate for different values of $q$. The error decreases when $q$ approaches to the extreme values between 0 and 1 . In view of this result, the $q$-iterative methods are calculated for a large value of $q=0.99999$, which will approximate the ordinary iterative methods. 


\begin{tabular}{cccc}
\hline \multicolumn{4}{c}{ List B (QAG1) } \\
\hline Nonlinear equation & True Solution & Approximate solution at $q=0.9999$ & Error \\
\hline Equation (51) & 1.20764782713091892701 & 1.20764782713091892700 & $7.187741 \mathrm{e}-21$ \\
Equation (52) & 0.10099792968574978895 & 0.10099792968574978895 & $3.394397 \mathrm{e}-28$ \\
Equation (53) & 1.92984624284786221849 & 1.92984624284786218283 & $3.565288 \mathrm{e}-17$ \\
\hline \multicolumn{5}{c}{ List C (QAG2) } \\
\hline Nonlinear equation & True Solution & Approximate solution at $q=0.9999$ & Error \\
\hline Equation (51) & 1.20764782713091892701 & 1.20764782713091892701 & $7.016521 \mathrm{e}-22$ \\
Equation (52) & 0.10099792968574978895 & 0.10099792968574978895 & $3.064831 \mathrm{e}-28$ \\
Equation (53) & 1.92984624284786221849 & 1.92984624284786221845 & $3.396321 \mathrm{e}-20$ \\
\hline
\end{tabular}

\subsection{Comparison of the Classical and q-Analogue of Iterative Methods}

Here, we check the robustness and efficiency of our new iterative methods by considering some of the nonlinear equations. Furthermore, we compare the standard Newton's method (NM), fourth order Chun method (CM) (see [3]), CAG1 and CAG2 with our new iterative methods QAG1 and QAG2. In Table 7, we display the number of iterations (IT), the approximate root $x_{n}$, the value $f\left(x_{n}\right)$ and $\delta$ be the distance between two successive estimations. It is important to mention that in order to get better computational results of the $q$-iterative methods, we take the value of $q=0.9999$.

$$
\begin{aligned}
& f_{1}(x)=x e^{x^{2}}-\sin ^{2} x+3 \cos (x)+5, \\
& f_{2}(x)=0.1056885297 x^{2}+\left(\frac{e^{x}-e^{-x}}{2}\right)-\sin (x), \\
& f_{3}(x)=0.986 x^{3}-5.181 x^{2}+9.067 x-5.289, \\
& f_{4}(x)=1,000,000 e^{x}+435,000\left(\frac{e^{x}-1}{x}\right)-1,564,000, \\
& f_{5}(x)=x^{3}+4 x^{2}-10, \\
& f_{6}(x)=x^{2}-e^{x}-3 x+2, \\
& f_{7}(x)=x^{2}-(1-x)^{5}, \\
& f_{8}(x)=\left(x^{3}-9 x^{2}+24 x-20\right)^{1 / 3}+e^{x / 2}, \\
& f_{9}(x)=\sqrt[3]{x^{3}-3 x^{2}}+\log (x+1) .
\end{aligned}
$$

\begin{tabular}{|c|c|c|c|c|}
\hline \multicolumn{5}{|c|}{$f_{1}(x)=x e^{x^{2}}-\sin ^{2} x+3 \cos x+5, x_{0}=-2$} \\
\hline Methods & IT & $x_{n}$ & $f\left(x_{n}\right)$ & $\delta=\left|x_{n}-x_{n-1}\right|$ \\
\hline NM & 8 & 1.2076478271309189 & $5.538944 \mathrm{e}-20$ & $4.261204 \mathrm{e}-11$ \\
\hline $\mathrm{CM}$ & 6 & 1.2076478271309189 & $1.063857 \mathrm{e}-17$ & $4.175854 \mathrm{e}-10$ \\
\hline CAG1 & 6 & 1.2076478271309189 & $6.780624 \mathrm{e}-34$ & $1.948602 \mathrm{e}-12$ \\
\hline QAG1 & 5 & 1.2076478271309189 & $4.435401 \mathrm{e}-12$ & $7.441078 \mathrm{e}-05$ \\
\hline CAG2 & 5 & 1.2076478271309189 & $1.009799 \mathrm{e}-37$ & $1.383883 \mathrm{e}-10$ \\
\hline QAG2 & 5 & 1.2076478271309189 & $1.424874 \mathrm{e}-20$ & $1.175311 \mathrm{e}-10$ \\
\hline \multicolumn{5}{|c|}{$f_{2}(x)=0.1056885297 x^{2}+\left(\frac{e^{x}-e^{-x}}{2}\right)-\sin (x), x_{0}=-1.2$} \\
\hline NM & 9 & 0.3170617745729571 & $5.220965 \mathrm{e}-21$ & $1.571531 \mathrm{e}-10$ \\
\hline $\mathrm{CM}$ & 7 & 0.3170617745729571 & $2.444123 e-46$ & $4.508430 \mathrm{e}-16$ \\
\hline CAG1 & 6 & 0.3170617745729575 & $1.510838 \mathrm{e}-17$ & $1.782637 \mathrm{e}-06$ \\
\hline QAG1 & 6 & 0.3170617745730157 & $1.964445 \mathrm{e}-15$ & $1.741348 \mathrm{e}-06$ \\
\hline CAG2 & 5 & 0.3170617745729571 & $3.494619 \mathrm{e}-19$ & $1.009576 \mathrm{e}-05$ \\
\hline QAG2 & 5 & 0.3170617745729571 & $2.502232 \mathrm{e}-19$ & $1.000084 \mathrm{e}-05$ \\
\hline
\end{tabular}

Table 7. The methods and their IT, $x_{n}, f\left(x_{n}\right)$ and $\delta$. 
Table 7. Cont.

\begin{tabular}{|c|c|c|c|c|}
\hline \multicolumn{5}{|c|}{$f_{3}(x)=0.986 x^{3}-5.181 x^{2}+9.067 x-5.289, x_{0}=3.10$} \\
\hline NM & 10 & 1.9298462428478622 & $1.815641 \mathrm{e}-25$ & $5.866916 \mathrm{e}-13$ \\
\hline $\mathrm{CM}$ & 7 & 1.9298462428478621 & $6.121465 \mathrm{e}-18$ & $2.408838 \mathrm{e}-09$ \\
\hline CAG1 & 7 & 1.9298462428478622 & $1.803102 \mathrm{e}-28$ & $3.036789 \mathrm{e}-10$ \\
\hline QAG1 & 7 & 1.9298462428478622 & $3.081547 \mathrm{e}-18$ & $2.566058 \mathrm{e}-11$ \\
\hline CAG2 & 6 & 1.9298462428478622 & $7.761545 \mathrm{e}-40$ & $5.605978 \mathrm{e}-11$ \\
\hline QAG2 & 6 & 1.9298462428478622 & $2.935505 \mathrm{e}-21$ & $2.073804 \mathrm{e}-11$ \\
\hline \multicolumn{5}{|c|}{$f_{4}(x)=1,000,000 e^{x}+435,000\left(\frac{e^{x}-1}{x}\right)-1,564,000, x_{0}=1.5$} \\
\hline NM & 7 & 0.1009979296857498 & $7.697779 \mathrm{e}-31$ & $1.104193 \mathrm{e}-18$ \\
\hline $\mathrm{CM}$ & 6 & 0.1009979296857498 & $2.569791 \mathrm{e}-33$ & $4.511244 \mathrm{e}-20$ \\
\hline CAG1 & 5 & 0.1009979296857498 & $5.620211 \mathrm{e}-45$ & $2.113407 \mathrm{e}-17$ \\
\hline QAG1 & 5 & 0.1009979296857498 & $4.545278 \mathrm{e}-22$ & $1.496790 \mathrm{e}-17$ \\
\hline CAG2 & 4 & 0.1009979296857498 & $3.875494 \mathrm{e}-41$ & $2.882365 \mathrm{e}-12$ \\
\hline QAG2 & 4 & 0.1009979296857498 & $4.103556 \mathrm{e}-22$ & $2.837594 \mathrm{e}-12$ \\
\hline \multicolumn{5}{|c|}{$f_{5}(x)=x^{3}+4 x^{2}-10, x_{0}=1$} \\
\hline NM & 5 & 1.2076478271309189 & $3.662513 e-21$ & $2.126976 \mathrm{e}-11$ \\
\hline $\mathrm{CM}$ & 41 & 1.2076478271309189 & $5.538944 \mathrm{e}-20$ & $4.261204 \mathrm{e}-11$ \\
\hline CAG1 & 4 & 1.3652300134140968 & $3.000665 \mathrm{e}-38$ & $1.557777 \mathrm{e}-13$ \\
\hline QAG1 & 4 & 1.3652300134140968 & $6.937438 \mathrm{e}-20$ & $9.377190 \mathrm{e}-13$ \\
\hline CAG2 & 3 & 1.3652300134140968 & $2.672414 \mathrm{e}-27$ & $1.361253 \mathrm{e}-07$ \\
\hline QAG2 & 3 & 1.3652300134140968 & $6.648073 \mathrm{e}-19$ & $1.349188 \mathrm{e}-07$ \\
\hline \multicolumn{5}{|c|}{$f_{6}(x)=x^{2}-e^{x}-3 x+2, x_{0}=2$} \\
\hline NM & 5 & 0.2575302854398608 & $3.439576 \mathrm{e}-27$ & $9.869210 \mathrm{e}-14$ \\
\hline $\mathrm{CM}$ & 5 & 0.2575302854398608 & $9.348485 \mathrm{e}-20$ & $3.638191 \mathrm{e}-10$ \\
\hline CAG1 & 4 & 0.2575302854398608 & $1.218871 \mathrm{e}-41$ & $5.694586 \mathrm{e}-14$ \\
\hline QAG1 & 4 & 0.2575302854398608 & $9.378610 \mathrm{e}-25$ & $4.284785 \mathrm{e}-14$ \\
\hline CAG2 & 3 & 0.2575302854398608 & $9.720474 \mathrm{e}-29$ & $2.979348 \mathrm{e}-07$ \\
\hline QAG2 & 3 & 0.2575302854398608 & $1.658292 \mathrm{e}-23$ & $2.973073 \mathrm{e}-07$ \\
\hline \multicolumn{5}{|c|}{$f_{7}(x)=x^{2}-(1-x)^{5}, x_{0}=0.9$} \\
\hline NM & 5 & 0.3459548158482420 & $6.819645 \mathrm{e}-17$ & $6.158927 \mathrm{e}-09$ \\
\hline $\mathrm{CM}$ & 6 & 0.3459548158482420 & $4.839061 \mathrm{e}-22$ & $1.160085 \mathrm{e}-11$ \\
\hline CAG1 & 4 & 0.3459548158482420 & $9.410608 \mathrm{e}-42$ & $1.327460 \mathrm{e}-14$ \\
\hline QAG1 & 3 & 0.3459548158482420 & 7.943736e-17 & $1.736512 \mathrm{e}-05$ \\
\hline CAG2 & 3 & 0.3459548158482420 & $1.606415 \mathrm{e}-38$ & $2.055302 \mathrm{e}-10$ \\
\hline QAG2 & 3 & 0.3459548158482420 & $1.855349 \mathrm{e}-23$ & $1.990689 \mathrm{e}-10$ \\
\hline \multicolumn{5}{|c|}{$f_{8}(x)=\left(x^{3}-9 x^{2}+24 x-20\right)^{1 / 3}+e^{x / 2}, x_{0}=2$} \\
\hline NM & & Fail & & \\
\hline $\mathrm{CM}$ & & Fail & & \\
\hline CAG1 & & Fail & & \\
\hline QAG1 & 4 & 0.9694264485832326 & 2.465462e-15 & $7.651474 \mathrm{e}-06$ \\
\hline CAG2 & & Fail & & \\
\hline QAG2 & 4 & 0.9694264485832314 & 7.378707e-25 & $1.231459 \mathrm{e}-10$ \\
\hline \multicolumn{5}{|c|}{$f_{9}(x)=\sqrt[3]{x^{3}-3 x^{2}}+\log (x+1), x_{0}=3$} \\
\hline NM & & Fail & & \\
\hline $\mathrm{CM}$ & & Fail & & \\
\hline CAG1 & & Fail & & \\
\hline QAG1 & 6 & 2.6925176762621718 & $1.218786 \mathrm{e}-16$ & $6.562094 \mathrm{e}-10$ \\
\hline CAG2 & & Fail & & \\
\hline QAG2 & 5 & 2.6925176762621717 & $3.027817 \mathrm{e}-17$ & $4.453735 \mathrm{e}-07$ \\
\hline
\end{tabular}

Table 7 compares the solutions obtained by using the classical and our the $q$-iterative methods. The results show that our $q$-analogue iterative methods QAG1 and QAG2 give the same results as the classical methods CAG1 and CAG2. The functions $f_{8}(x), f_{9}(x)$ are not differentiable at $x=2$ and $x=3$, respectively, when we choose $x=2$ and $x=3$ as initial guesses for $f_{8}(x)$ and $f_{9}(x)$, respectively. Then, the iterative methods: NM, CM, CAG1 and CAG2 fail, while the new iterative methods QAG1 and QAG2 are applicable and give rapid convergent results. 
Remark 1 (see [12]). The efficiency index is considered as $P^{\frac{1}{m}}$, where $P$ represents the order of the method and $m$ is the total number of function evaluations per iteration necessary by the method.

- $\quad$ Efficiency index of CAG1 is $3^{\frac{1}{3}}=1.442250$.

- Efficiency index of CAG2 is $4^{\frac{1}{4}}=1.414214$.

- Efficiency index of QAG1 is $3^{\frac{1}{2}}=1.442250$.

- Efficiency index of QAG2 is $4^{\frac{1}{4}}=1.414214$.

We conclude that the efficiency indexes calculated by QAG1 and QAG2 are the same as those calculated by CAG1 and CAG2.

\section{Generalization of the Iterative Scheme in $q$-Calculus}

In this section, based on our previous results, we determine the generalized $q$-iterative scheme. By adding the values of $x_{i} s^{\prime}(\forall i=1,2, \ldots, n)$ in (19), we obtain

$$
x_{1}+x_{2}+\cdots+x_{n}=x_{0}+M_{q}\left(x_{0}+x_{1}+\cdots+x_{n-1}\right) .
$$

From (22), we have

$$
\begin{aligned}
& x_{0}=\lambda-\frac{f(\lambda)}{D_{q} f(\lambda)}, \\
& x_{0}+x_{1}=x_{0}-\frac{f\left(x_{0}\right)}{D_{q} f(\lambda)}=x_{0}+M_{q}\left(x_{0}\right), \\
& x=x_{0}+x_{1}+x_{2}=x_{0}+x_{1}-\frac{f\left(x_{0}+x_{1}\right)}{D_{q} f(\lambda)}=x_{0}+M_{q}\left(x_{0}+x_{1}\right) .
\end{aligned}
$$

Now, if $x$ is approximated by

$$
\begin{aligned}
& x=x_{0}+x_{1}+\cdots+x_{n}=x_{0}+M_{q}\left(x_{0}+x_{1}+\cdots+x_{n-1}\right) \\
& x=x_{0}+x_{1}+\cdots+x_{n-1}-\frac{f\left(x_{0}+x_{1}+\cdots+x_{n-1}\right)}{D_{q} f(\lambda)} \\
& x=x_{0}+x_{1}+\cdots+x_{n}=x_{0}+x_{1}+\cdots+x_{n-1}-\frac{f\left(x_{0}+x_{1}+\cdots+x_{n-1}\right)}{D_{q} f(\lambda)} .
\end{aligned}
$$

Therefore, (54) gives the following iterative scheme:

$$
x_{n}=-\frac{f\left(x_{0}+x_{1}+\cdots+x_{n-1}\right)}{D_{q} f(\lambda)} \quad(\forall n=1,2,3, \ldots) ;
$$

$$
\left\{\begin{array}{l}
x_{0}=\lambda-\frac{f(\lambda)}{D_{q} f(\lambda)} \\
x_{0}+x_{1}=x_{0}-\frac{f\left(x_{0}\right)}{D_{q} f(\lambda)^{\prime}} \\
x_{0}+x_{1}+x_{2}=x_{0}+x_{1}-\frac{f\left(x_{0}+x_{1}\right)}{D_{q} f(\lambda)}, \\
\vdots \\
x_{0}+x_{1}+x_{2}+\ldots+x_{n-1}+x_{n}=x_{0}+x_{1}+x_{2}+\ldots+x_{n-1}-\frac{f\left(x_{0}+x_{1}+x_{2}+\ldots+x_{n-1}\right)}{D_{q} f(\lambda)} .
\end{array}\right.
$$


This formulation allows us to suggest the following generalized $q$ iterative method:

$$
\left\{\begin{array}{l}
y_{0}=x_{m}, \\
y_{1}=y_{0}-\frac{f\left(y_{0}\right)}{D_{q} f\left(y_{0}\right)}, \\
y_{2}=y_{1}-\frac{f\left(y_{1}\right)}{D_{q} f\left(y_{0}\right)}, \\
y_{3}=y_{2}-\frac{f\left(y_{2}\right)}{D_{q} f\left(y_{0}\right)}, \\
\vdots \\
y_{n+1}=y_{n}-\frac{f\left(y_{n}\right)}{D_{q} f\left(y_{0}\right)}, \\
x_{m+1}=y_{n+1} .
\end{array}\right.
$$

The order of convergence of the iterative scheme is $n+2$ for $n=0,1,2, \ldots$ and the number of functional evaluations is also $n+2$ as well.

\section{Conclusions}

The main target of this article is to introduce novel algorithms for solution of the nonlinear equations in the context of the $q$-calculus. The new algorithms are introduced by using the Daftardar-Jafari decomposition technique. The comparison of these newly established algorithms with the classical methods reflects that the proposed $q$-iterative methods are reliable and best alternatives to the already known algorithms. The computational results conclude that the $q$-analogue of the iterative methods for solving the algebraic nonlinear equations generate the same results as the classical methods, but convergence rate towards approaching the root is higher than convergence rate suggested by the classical methods. Furthermore, the errors associated with the proposed methods are comparatively lesser by the appropriately chosen value of $q$ being close to one. The difficulty in this method, which needs future investigation, is that we need to estimate the value of $q \in(0,1)$.

Author Contributions: Conceptualization, G.S., P.O.M. and M.A.N.; methodology, G.S., P.O.M. and D.Y.S.; software, P.O.M., D.Y.S. and M.A.N.; validation, P.O.M., D.Y.S. and M.S.O.; formal analysis, P.O.M. and D.Y.S.; investigation, P.O.M.; resources, P.O.M. and M.A.N.; data curation, G.S., P.O.M. and D.Y.S.; writing—original draft preparation, G.S. and D.Y.S.; writing—review and editing, G.S., P.O.M. and M.S.O.; visualization, D.Y.S.; supervision, P.O.M., M.A.N. and D.Y.S. All authors have read and agreed to the final version of the manuscript.

Funding: This research received no external funding.

Institutional Review Board Statement: Not applicable.

Informed Consent Statement: Not applicable.

Data Availability Statement: Not applicable.

Acknowledgments: We would like to express our sincere gratitude to the anonymous referees for their helpful comments that will help to improve the quality of the manuscript.

Conflicts of Interest: The authors declare no conflict of interest.

\section{References}

1. Mohammed, P.O.; Machado, J.A.T.; Guirao, J.L.G.; Agarwal, R.P. Adomian decomposition and fractional power series solution of a class of nonlinear fractional differential equations. Mathematics 2021, 9, 1070. [CrossRef]

2. Mohammed, P.O.; Alqudah, M.A.; Hamed, Y.S.; Kashuri, A.; Abualnaja, K.M. Solving the modified regularized long wave equations via higher degree B-spline algorithm. J. Funct. Space 2021, 2021, 5580687.

3. Chun, C. Iterative methods improving Newton's method by the decomposition method. Comput. Math. Appl. 2005, 50, 1559-1568. [CrossRef]

4. Noor, M.A.; Waseem, M.; Noor, K.I.; Ali, M.A. New iterative technique for solving nonlinear equations. Appl. Math. Comput. 2015, $265,1115-1129$. 
5. Hamasalh, F.K.; Mohammed, P.O. Generalized quartic fractional spline interpolation with applications. Int. J. Open Probl. Compt. Math. 2015, 8, 67-80. [CrossRef]

6. Solaiman, O.S. Two new efficient sixth order iterative methods for solving nonlinear equations. J. King. Saud Uni. 2019, 31, 701-705. [CrossRef]

7. Sana, G.; Noor, M.A.; Noor, K.I. Some multistep iterative methods for nonlinear equation using quadrature rule. Int. J. Anal. Appl. 2020, 18, 920-938.

8. Alqudah, M.A.; Mohammed, P.O.; Abdeljawad, T. Solution of singular integral equations via Riemann-Liouville fractional integrals. Math. Prob. Eng. 2020, 2020, 1250970. [CrossRef]

9. Wu, J.; Yuan, J.; Gao, W. Analysis of fractional factor system for data transmission in SDN. Appl. Math. Nonlinear Sci. 2019, 4, 191-196. [CrossRef]

10. Kurt, A.; Şenol, M.; Tasbozan, O.; Chand, M. Two reliable methods for the solution of fractional coupled Burgers' equation arising as a model of Polydispersive sedimentation. Appl. Math. Nonlinear Sci. 2019, 4, 523-534. [CrossRef]

11. Touchent, K.A.; Hammouch, Z.; Mekkaoui, T. A modified invariant subspace method for solving partial differential equations with non-singular kernel fractional derivatives. Appl. Math. Nonlinear Sci. 2020, 5, 35-48. [CrossRef]

12. Traub, J.F. Iterative Methods for Solution of Equations; Prentice-Hall: Englewood Cliffs, NJ, USA, 1964.

13. Cordero, A.; Torregrosa, J.R. Variants of Newton's method using fifth-order quadrature formulas. Appl. Math. Comput. 2007, 190, 686-698.

14. Frontini, M.; Sormani, E. Some variants of Newtons method with third order convergence. Appl. Math. Comput. 2003, 140, 419-426.

15. Hasanov, V.I.; Ivanov, I.G.; Nedzhibov, G. A new modification of Newton method. Appl. Math. Eng. 2002, 27, $278-286$.

16. Weerakoon, S.; Fernando, T.G.I. A variant of Newton's method with accelerated third-order convergence. Appl. Math. Lett. 2000, 13, 87-93. [CrossRef]

17. Ozban, A.Y. Some New variants of Newton's method. Appl. Math. Lett. 2004, 17, 677-682. [CrossRef]

18. Daftardar-Gejji, V.; Jafari, H. An iterative method for solving nonlinear functional equations. J. Math. Anal. Appl. 2006, 316, 753-763. [CrossRef]

19. Adomian, G. Nonlinear Stochastic Systems and Applications to Physics; Springer Science \& Business Media: Dordrecht, The Netherlands, 1989; Volume 46.

20. Saqib, M.; Iqbal, M. Some multi-step iterative methods for solving nonlinear equations. Open J. Math. Sci. 2017, 1, 25-33. [CrossRef]

21. Ali, F.; Aslam, W.; Ali, K.; Anwar, M.A.; Nadeem, A. New family of iterative methods for solving nonlinear models. Discret. Dyn. Nat. Soc. 2018, 2018, 9619680. [CrossRef]

22. Ali, F.; Aslam, W.; Khalid, I.; Nadeem, A. Iteration methods with an auxiliary function for nonlinear equations. J. Math. 2020, 2020, 7356408. [CrossRef]

23. Ernst, T. A New Notation for q-Calculus a New q-Taylor's Formula; UUDM Report; Department of Mathematics, Uppsala University: Uppsala, Sweden, 1999; pp. 1-28.

24. Koelink, E. Eight lectures on quantum groups and q-special functions. Rev. Colomb. Mat. 1996, 30, 93-180.

25. Alqudah, M.A., Kashuri, A., Mohammed, P.O.; Abdeljawad, T.; Raees, M.; Anwar, M.; Hamed, Y.S. Hermite-Hadamard integral inequalities on coordinated convex functions in quantum calculus. Adv. Differ. Equ. 2021, 2021, 264. [CrossRef]

26. Eryilmaz, A. Spectral analysis of q-sturm-liouville problem with the spectral parameter in the boundary condition. J. Funct. Spaces 2012, 2012, 736437. [CrossRef]

27. Erzan, A. Finite $q$-differences and the discrete renormalization group. Phys. Lett. A 1997, 4-6, 235-238. [CrossRef]

28. He, J.H. A new iteration method for solving algebraic equations. Appl. Math. Comput. 2003, 135, 81-84. [CrossRef]

29. Koornwinder, T.H.; Swarttouw, R.F. On $q$-analogues of the Fourier and Hankel transforms. Trans. Am. Math. Soc. 1992, 333, 445-461.

30. Jackson, F.H. A q-form of Taylors formula. Mess. Math. 1909, 38, 62-64.

31. Jing, S.C.; Fan, H.Y. q-Taylor's Formula with its $q$ remainder. Commun. Theor. Phys. 1995, 23, 117-120. [CrossRef]

32. Ernst, T. A method for $q$-calculus. J. Nonlinear Math. Phys. 2003, 10, 487-525. [CrossRef]

33. Singh, P.; Mishra, P.K.; Pathak, R.S. q-iterative methods. IOSR J. Math. 2013, 9, 6-10. [CrossRef]

34. Jafari, H.; Johnston, S.J.; Sani, S.M.; Baleanu, D. A decomposition method for solving q-difference equations. Appl. Math. Inf. Sci. 2015, 9, 2917-2920.

35. Noor, M.A.; Noor, K.I. Three step iterative methods for nonlinear equations. Appl. Math. Comput. 2006, $183,322-327$.

36. Ullah, M.Z.; Ahmad, F.; Jbbar, M.A.A.A. A correction note on three-step iterative methods for nonlinear equations and generalization of method. J. Mod. Methods Num. Anal. 2014, 5, 10-16. [CrossRef]

37. Kac, V.; Cheung, P. Quantum Calculus; Springer: New York, NY, USA, 2002.

38. Cherruault, Y. Convergence of Adomians method. Kybernetes 1989, 18, 31-38. [CrossRef]

39. Burden, R.L.; Faires, J.D. Numerical Analysis; PWS Publishing Company: Boston, MA, USA, 2001.

40. Waals, V.D.; Diderik, J. Over de Continuiteit van den Gasen Vloeistoftoestand (on the Continuity of the Gas and Liquid State). Ph.D. Thesis, University of Leiden, Leiden, The Netherlands, 1873. 